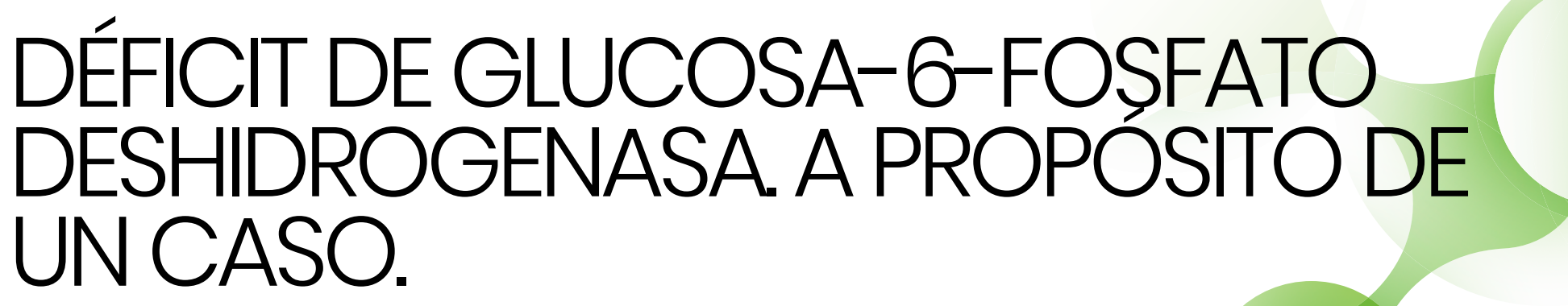

\title{
GLUCOSE-6-PHOSPHATE DEHYDROGENASE DEFICIENCY. CASE REPORT.
}

\section{Arroyo Argüelles JM, de Vicente Ortega A, Frutos Muñoz L}

Hospital Universitario de Jaén.

\section{Resumen}

Se presenta el caso de una mujer que ingresa por cuadro clínico consistente en ictericia y anemia, siendo diagnosticada de crisis hemolítica aguda secundaria a la ingesta de habas.

Palabras clave: favismo, déficit de glucosa-6-fosfato deshidrogenasa, hemólisis.

\section{Abstract}

We report the case of a woman who is hospitalized because of jaundice and anemia, being diagnosed of an acute hemolytic crisis due to beans intake.

Keywords: favism, glucose-6-phosphate dehydrogenase deficiency, hemolysis.

\section{CORRESPONDENCIA}

José María Arroyo Argüelles

Hospital Universitario de Jaén

23007. Jaén

imarrovo94@gmail.com

Fecha de envío: 30/06/2021

Fecha de aceptación: 20/08/2021

\section{Introducción}

La deficiencia de glucosa-6-fosfato deshidrogenasa (G6PDH) en individuos genéticamente predispuestos puede producir una crisis hemolítica aguda en ciertas situaciones, como son la ingesta de habas (favismo), infecciones o fármacos ${ }^{1}$.

Para el diagnóstico es necesaria la determinación de la actividad enzimática de la G6PDH y el tratamiento suele ser conservador, con resolución de la crisis y buena evolución en la mayoría de los casos.

\section{Caso Clínico}

Presentamos el caso de una mujer de 61 años, con antecedentes personales de trastorno depresivo y fibromialgia, que acude al hospital por dolor abdominal, coluria y tinte ictérico de 24 horas de evolución.

Indagando en la anamnesis, la mujer refiere ingesta de habas frescas en las 48 horas previas y antecedentes familiares de favismo.

A la exploración física presenta buen estado general, estabilidad hemodinámica e ictericia cutánea franca, con abdomen blando, depresible, no doloroso a la palpación.

Se le solicita una analítica urgente, destacando en el hemograma la presencia de anemia ( $\mathrm{Hb} 10.8 \mathrm{~g} / \mathrm{dL}$ ) normocítica 
(VCM $94.6 \mathrm{fL})$, un aumento de reticulocitos $(3,42 \%)$ y leucocitosis asociada. En la bioquímica llama la atención una bilirrubina total de $8.4 \mathrm{mg} / \mathrm{dL}$, a expensas de bilirrubina indirecta $(7 \mathrm{mg} / \mathrm{dL})$. Así mismo, se objetiva unos niveles de lactato deshidrogenasa (LDH) de $4.130 \mathrm{U} / \mathrm{L}$ y haptoglobina de $9 \mathrm{mg} / \mathrm{dL}$.

A la vista de los resultados analíticos, se solicita una ecografía abdominal, con diagnóstico de esteatosis, sin otros hallazgos; así como un test de Coombs directo, que resulta negativo. Se realiza un frotis de sangre periférica, visualizando una marcada anisopoiquilocitosis.

Ante la sospecha de anemia hemolítica por trastorno enzimático se solicitó la determinación de glucosa-6-fosfato deshidrogenasa, con resultado deficitario de la enzima.

La paciente presentó buena evolución con tratamiento conservador en planta de hospitalización, siendo dada de alta y permaneciendo asintomática desde entonces hasta el momento actual.

\section{Discusión}

El déficit de glucosa-6-fosfato deshidrogenasa es la causa más frecuente de anemia hemolítica enzimopática ${ }^{2}$ y se transmite mediante herencia ligada al cromosoma $\mathrm{X}$, afectando a la mayoría de los casos a varones.

La G6PDH es una enzima fundamental en el metabolismo energético del hematíe. Su déficit produce una disminución del poder reductor del eritrocito debido a una disminución en la síntesis de NAPDH, de tal forma que determinados agentes oxidantes actuarán sobre la hemoglobina, desnaturalizándola y produciendo hemólisis.

La disminución la actividad de la enzima permanece asintomática en el individuo hasta que éste entra en contacto con ciertos factores desencadenantes como son las infecciones, favismo (ingestión o inhalación de polen de habas, guisantes o alcachofas) o toma de fármacos (dapsona, nitrofurantoína, sulfamidas, primaquina...), momento en el que tendrá lugar la crisis hemolítica.

La clínica es muy variable, desde casos asintomáticos hasta crisis hemolíticas graves, siendo habitual la triada anemia, ictericia $y$, frecuentemente, esplenomegalia. En ocasiones se objetiva coluria debido a la hemoglobinuria y, de manera muy poco habitual, puede incluso llegar a observarse un fallo renal agudo ${ }^{3}$.

Como consecuencia de la destrucción de hematíes, en las pruebas complementarias destacan datos analíticos de hemólisis (anemia, elevación de la bilirrubina a expensas de la bilirrubina indirecta, incremento de la LDH sérica y una disminución de la haptoglobina libre en plasma).

La evolución es favorable en la mayoría de los casos con tratamiento conservador y sin ningún tratamiento específico, siendo innecesaria la esplenectomía (la cual sólo estaría indicada en pacientes con hemólisis crónica).

El paciente debe saber qué conductas predisponen a la crisis hemolítica y tratar de evitarlas. Estas conductas incluyen la ingesta de alimentos como habas o guisantes, así como la toma de ciertos fármacos, habiéndose demostrado una clara asociación con el azul de metileno, la nitrofurantoína, la fenazopiridina, la primaquina, la dapsona, la rasburicasa y el azul de toluidina ${ }^{4}$. La prevención es la estrategia terapéutica más eficaz ${ }^{5}$.

\section{Bibliografía}

1. López Mas C, Sanchis Yago B, Sanz de Miguel P. Favismo: A propósito de un caso. Revista Atalaya Médica. 2014; 5: 38-42.

2. Luzzatto $L$ and Arese P. Favism and Glucose-6-Phosphate Dehydrogenase Deficiency. The New England Journal of Medicine 2018; 378:60-71.

3. Torres C D, Chandía C M. Insuficiencia renal aguda secundaria como manifestación inicial de favismo en adulto mayor. Rev Med Chilen 2012; 140:1043-1045.

4. Youngster I et al. Medications and Glucose-6-Phosphate Dehydrogenase Deficiency. Drug Saf 2010; 33 (9):713-726.

5. Bello Gutiérrez P, Mohameda Dafa L. Déficit de glucosa-6-fosfato deshidrogenasa: revisión a propósito de un caso. Revista de pediatría en Atención Primaria. 2015; 17:361-8. 